\title{
Twin-occlusion Prosthesis in a Class III Hemimandibulectomy Patient
}

\author{
Cora A Coutinho ${ }^{1}$, Divya Hegde ${ }^{2}$, Chottakyatanahalli R Vijayalakshmi ${ }^{3}$, Ruchika Iyer ${ }^{4}$, Akansha Priya ${ }^{5}$
}

\begin{abstract}
Discontinuity of the mandible results in deviation of remaining mandible toward the resected side. There are many ways of rehabilitating a hemimandibulectomy patient. The patient described in this case report presented with early squamous cell carcinoma of left mandibular alveolus underwent class III hemimandibulectomy and reported to the department of prosthodontics for rehabilitation of the defect as he faced difficulties in mastication and was also concerned about esthetics. This case report describes a technique for rehabilitating a hemimandibulectomy with complete dentures along with twin occlusion.

Keywords: Hemimandibulectomy, Mandibular deviation, Paired occlusion, Twin occlusion.

International Journal of Prosthodontics and Restorative Dentistry (2020): 10.5005/jp-journals-10019-1257
\end{abstract}

\section{BACKGROUND}

Fabrication of functional complete dentures for edentulous patients who have undergone hemimandibulectomy is a very arduous and demanding endeavor. The most challenging situation encountered during this procedure is the deviation of the mandible to the resected side. The deviation of the mandible to the resected side is directly proportional to the loss of tissues in the area hemimandibulectomy has been performed. ${ }^{1}$

In cases with Cantor and Curtis classes II, III, IV, and V, guide flange prosthesis would be a treatment modality. For guide flange prosthesis to be effective, the sufficient number of posterior teeth that are periodontally sound should be present in the opposite arch. ${ }^{2}$ In patients where reconstruction is not done after resection of the mandible, scar tissue formation occurs over a period of time that stiffens the tissues and worsens prosthetic rehabilitation, leading to compromised treatment planning. Various prosthetic treatments are available and depending upon the clinical situation, appropriate option should be selected. Swoop proposed the use of a Palatal Ramp, ${ }^{3}$ and Rosenthal suggested the use of twin occlusion. ${ }^{4,5}$ Various other authors too followed Rosenthal by modifying palatal ramp and utilizing multiple maxillary teeth in the form of twin rows on the untreated side. ${ }^{6,7}$ Mathew and Thomas delivered a Guiding Flange Prosthesis to a Hemimandibulectomy patient. ${ }^{8}$ Sharma et al. rehabilitated a hemimandibulectomy patient who was partially edentulous with twin occlusion prosthesis. ${ }^{9}$ Ruby et al. fabricated maxillary and mandibular acrylic complete denture using dynamic functional impression technique and using neutral zone to rehabilitate an edentulous hemimandibulectomy patient. ${ }^{10}$ This case report describes prosthodontic management of a patient who has undergone hemimandibulectomy and was rehabilitated with complete dentures using two rows of maxillary posterior teeth on unresected side/twin occlusion.

\section{Case Description}

A 74-year-old male patient reported to the department of prosthodontics with the chief complaint of difficulty in eating and poor appearance and wanted replacement of teeth. On eliciting the history, the patient revealed the habit of tobacco chewing for
${ }^{1-5}$ Department of Prosthodontics, Bangalore Institute of Dental Sciences and Research Centre, Bengaluru, Karnataka, India

Corresponding Author: Cora A Coutinho, Department of Prosthodontics, Bangalore Institute of Dental Sciences and Research Centre, Bengaluru, Karnataka, India, Phone: +91 9921044472, e-mail: coraabigail25@gmail.com

How to cite this article: Coutinho CA, Hegde D, Vijayalakshmi CR, et al. Twin-occlusion Prosthesis in a Class III Hemimandibulectomy Patient. Int J Prosthodont Restor Dent 2020;10(1):35-38.

Source of support: Nil

Conflict of interest: None

10 years and was diagnosed with early squamous cell carcinoma involving left mandibular alveolus. Left-side hemimandibulectomy was performed 1 year ago; and after resection, reconstruction was not done, which resulted in greater deviation owing to the scar tissue formed over a period of time, leading to compromised treatment planning. Patient also underwent radiation therapy.

Extraoral examination showed facial asymmetry in the lower third of the face, decreased mouth opening of $32 \mathrm{~mm}$, significant deviation of mandible to left side of mouth opening, and drooping of the corner of the mouth which was more prominent on the left side.

Intraoral examination revealed completely edentulous maxillary and mandibular arches with a left mandibular defect from the midline. Both the ridges were smooth, round, well-keratinized mucosa with sufficient height and width for support (Fig. 1).

The case was diagnosed as Cantor and Curtis Class III mandibular defect based on clinical and radiographic examination (Fig. 2).

Preliminary impressions were made with irreversible hydrocolloid material (Algitex; DPI, Mumbai, India) using stock trays and casts were poured with type II dental plaster. On the maxillary and mandibular casts, a custom tray was fabricated with self-cure acrylic resin (Cold Cure; DPI RR, Dentsply, India) and border molding was performed. Final impressions were made with zinc oxide eugenol impression paste (Impression Paste; DPI, Mumbai, India). Denture bases were fabricated and wax occlusal rims were 

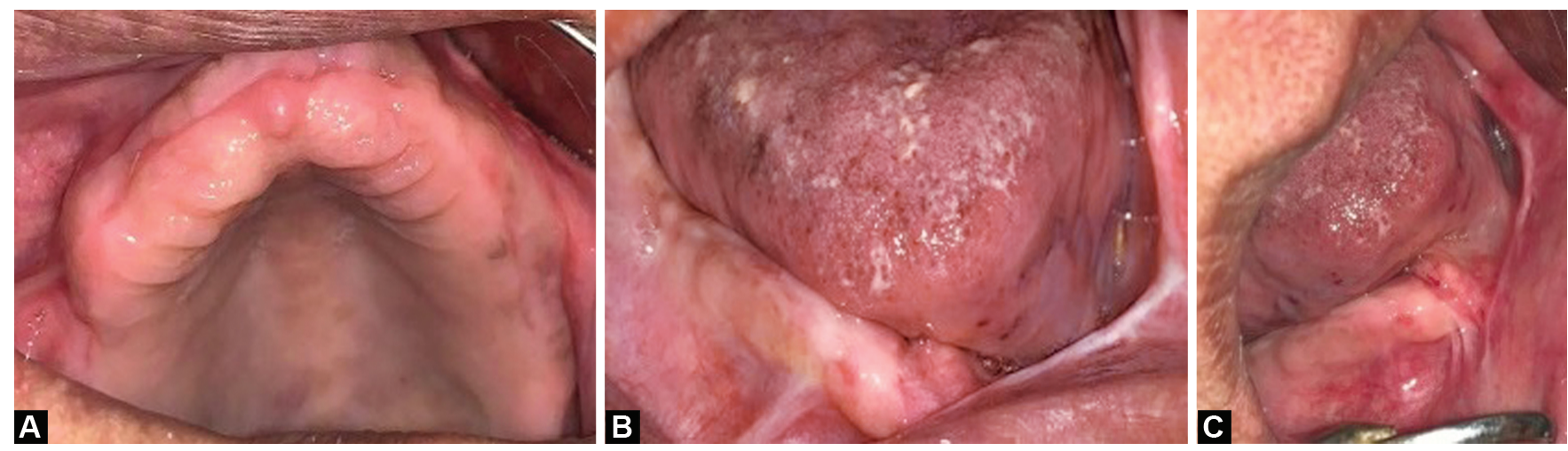

Figs 1 A to C: (A) Intraoral view of maxilla; (B) Intraoral view of mandible; (C) Intraoral view of mandible

made. A functional occlusal record was obtained in wax placed lingual to the maxillary posterior occlusal rim on the opposite side of the defect region and used as an index to arrange the palatal row of the teeth. The patient's tactile sense was used to assess the vertical dimension of occlusion. The patient was advised to move his mandible as far as possible toward the resected side and then gently close his mandibular jaw into the position to record a functional maxillomandibular relationship. After articulation, two sets of nonanatomic teeth (Premadent, New Delhi, India) were selected. Two rows of teeth were arranged in the posterior region of edentulous maxilla on the unaffected side. First row of teeth were arranged as per contour of the patients ridge and the other set were arranged palatal to the first row on the unaffected side in the maxillary arch on which the mandibular teeth would occlude. The teeth arrangement in the mandible would have ended at 32 region and as this would lead to an abrupt termination of the denture, three teeth were added to that region for esthetic purpose and were in mild contact. Arrangement was verified while trying for esthetics, phonetics. and occlusion (Figs 3 to 5). The processed dentures were evaluated intraorally for occlusal adjustments and border overextension (Figs 6 and 7). Due to his prominent maxilla, the labial flange was reduced to enhance his esthetics. Postinsertion instructions were given to the patient and was advised not to masticate on the defect side. He was instructed to do mouth opening and closing exercises to improve the neuromuscular coordination. The patient was periodically followed up after 1 day, 1 week, 1 month, and 3 months. Initially the patient experienced difficulty in using the denture but over the period of time he showed improvement in mastication and phonetics, and by 3 months he was satisfied functionally and psychologically (Figs 8 and 9).

\section{Discussion}

Greater the tissue loss, greater will be the mandibular deviation to the resected side, thereby compromising the prognosis of the treatment. ${ }^{11}$ Resected mandible along with tissue loss causes rotation of the mandibular plane on the defect side. The suprahyoid muscle pull causes inferior displacement and rotation of the condyle, thereby causing an anterior open bite. ${ }^{12}$ According to Beumer et al., it was suggested that following maximum opening, the patient is asked to manipulate the mandible by grasping the chin and moving the mandible away from the surgical side. These movements tend to loosen scar contracture and improve maxillomandibular relationships. ${ }^{13}$ Dentulous patients can be retrained to achieve acceptable

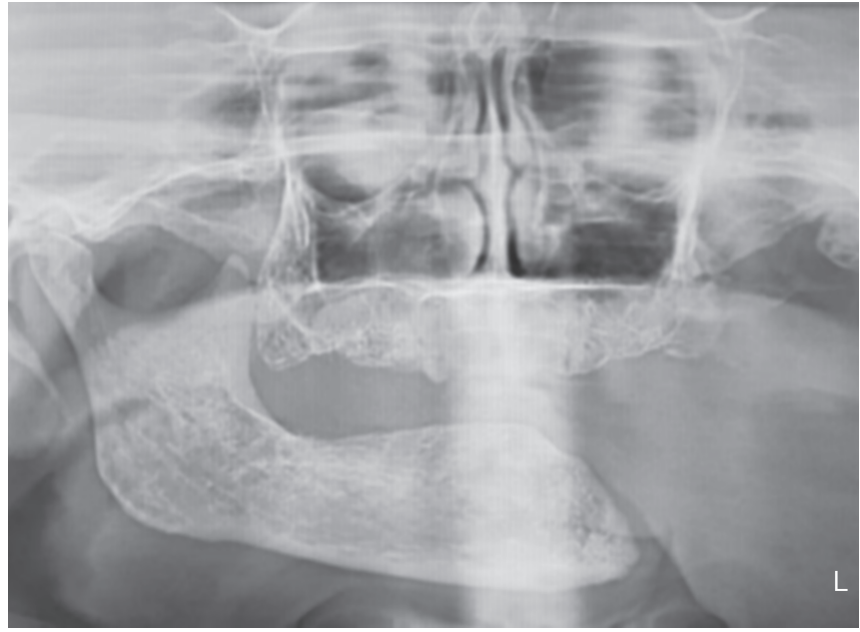

Fig. 2: Orthopantomogram showing the mandibular resection on the left side

maxillomandibular relationship with the help of appliance like guide plane. However, it cannot be used in edentulous patients. Hence, these patients cannot achieve adequate maxillomandibular relationship. ${ }^{7}$

In this case report, the definitive treatment to meet the functional and esthetic requirements of the edentulous hemimandibulectomy patient would have been an implant-supported prosthesis. ${ }^{14}$ But since the patient had restrictions to undergo another surgery owing to financial constraints, an acrylic complete denture with two rows of teeth on the maxillary denture on the unresected side of the mandible was given. The palatal row of teeth intercuspated with the mandibular teeth and thus improved mastication and the buccal row of teeth supported the cheeks. ${ }^{1}$ Acrylic denture base resin was chosen as a material of choice for the complete dentures because acrylic is esthetic, light in weight, less expensive, and easy to fabricate and repair.

\section{Conclusion}

Reconstruction and rehabilitation of a completely edentulous patient with hemimandibulectomy defects poses a special clinical challenge. The treatment modality using a twin-occlusion complete denture to the patient gave a significant improvement in mastication, speech, and esthetics. 


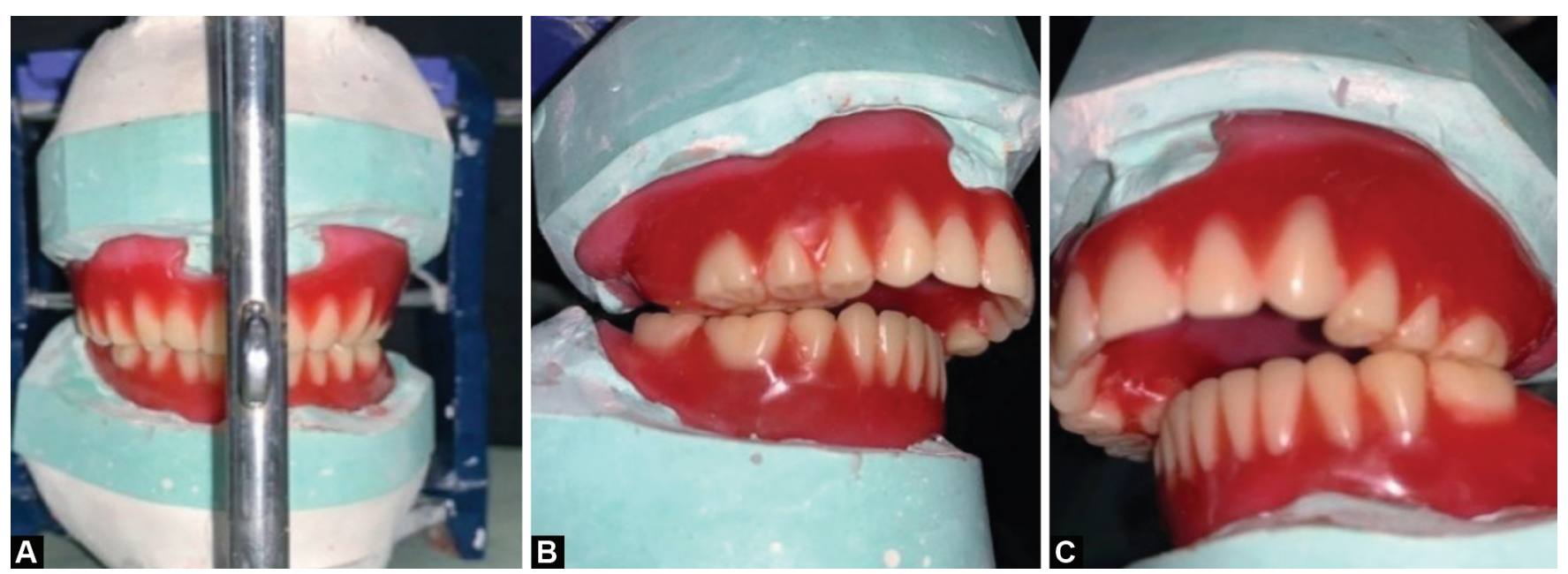

Figs 3A to C: (A) Teeth arrangement done (frontal view); (B) Teeth arrangement opposite to the defect; (C) Teeth arrangement on the defect side

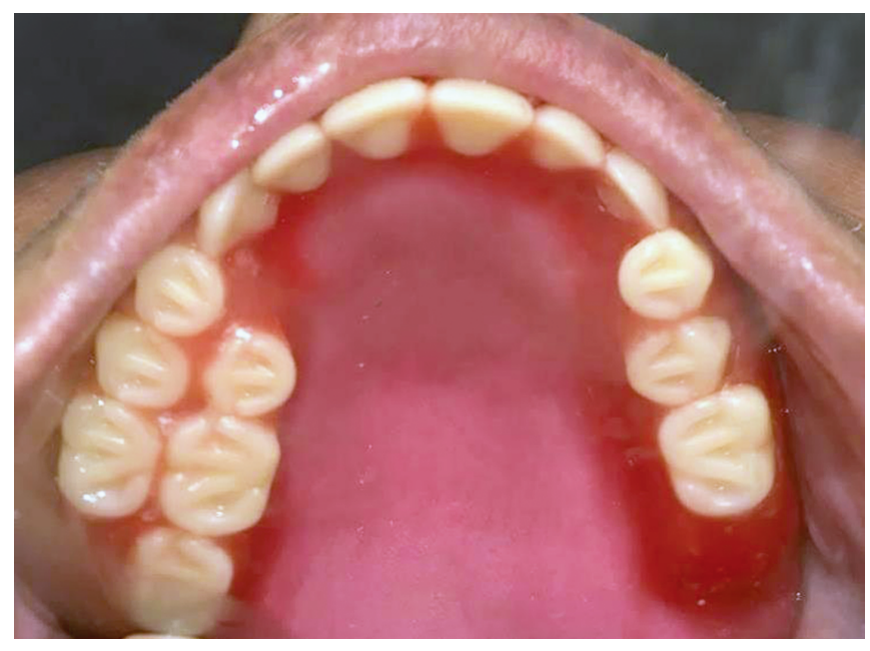

Fig. 4: Try-in stage, intraoral view showing twin occlusion on the opposite side of the defect

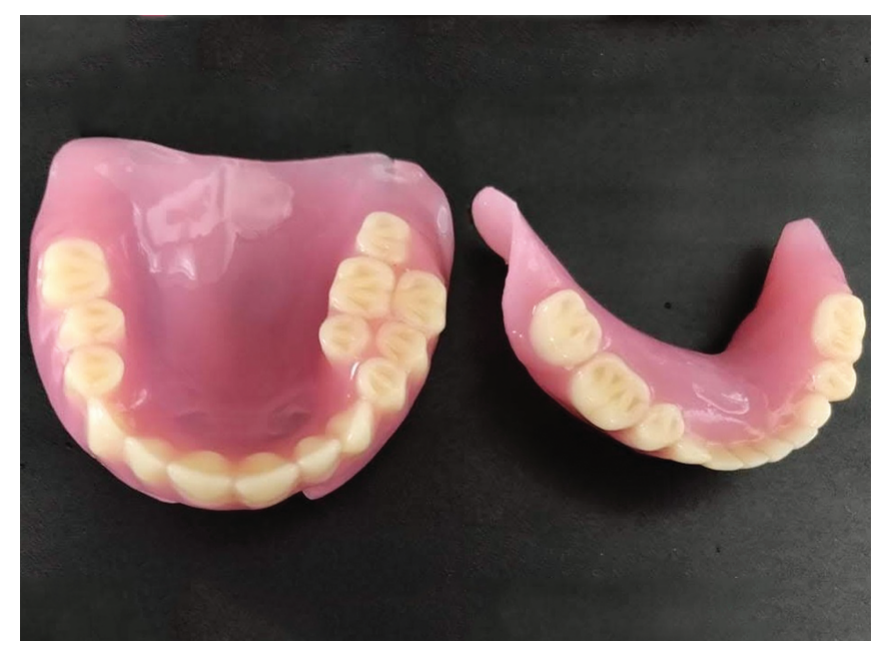

Fig. 6: Final denture

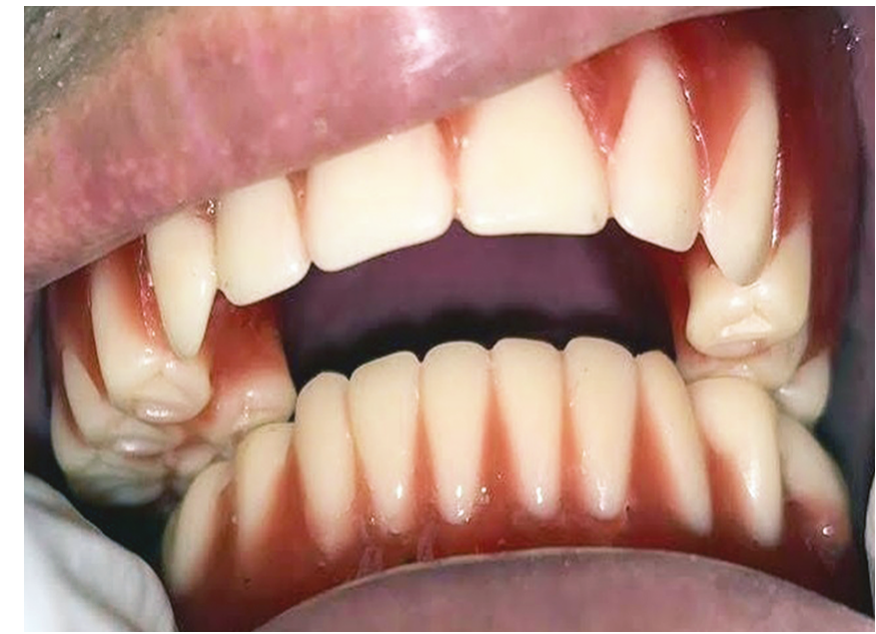

Fig. 5: Try-in stage, intraoral view showing the occlusion

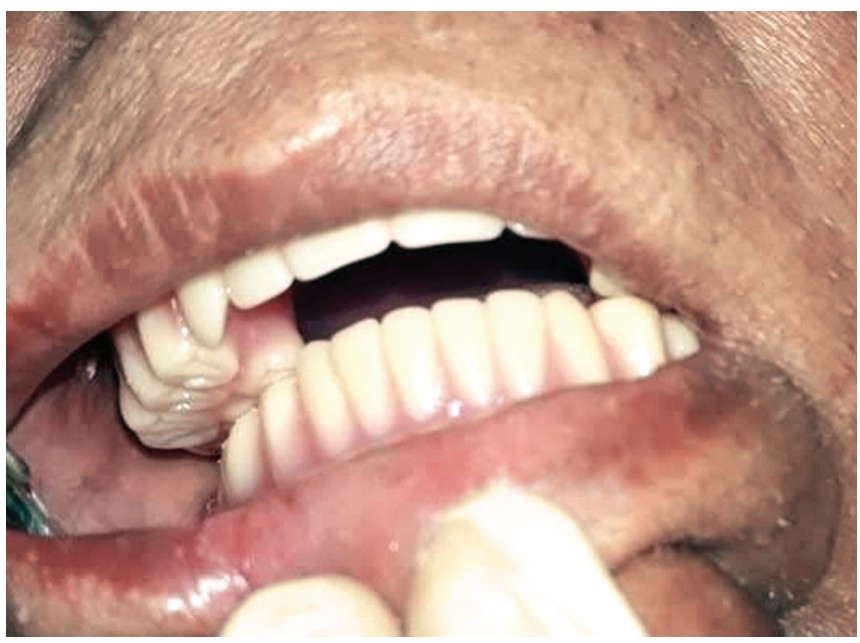

Fig. 7: Intraoral view showing the occlusion with the final denture 


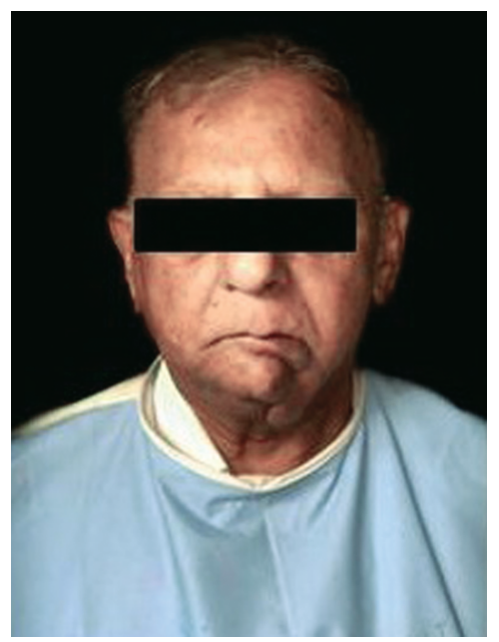

Fig. 8: Pretreatment

\section{References}

1. Maxillofacial rehabilitation, In: Beumer J, Curtis T, Firtell D St. Louis: Mosby; 1979. p. 90-169.

2. Cantor R, Curtis TA. Prosthetic management of edentlous mandibulectomy patients. part 1. Anatomic, physiologic and psychologic consideration. J Prosthet Dent 1971;25(4):446-457. DOI: 10.1016/0022-3913(71)90236-8.

3. Swoope CC. Prosthetic management of resected edentulous mandible. J Prosthet Dent 1969;21(2):197-202. DOI: 10.1016/00223913(69)90092-4.

4. Rosenthal LE. The edentulous patient with jaw defects. Dent Clin N Am 1994;8:773-779.

5. Sureja R, Naveen YG, Sethuraman R, et al. Twin occlusion prosthesis: a ray of hope for hemimandibulectomy patient-a case report. Eur J Dent Ther Res 2014;3:231-233.

6. Marathe AS, Kshirsagar PS. A systematic approach in rehabilitation of hemimandibulectomy: a case report. J Indian Prosthodont Soc 2016;16(2):208-212. DOI: 10.4103/0972-4052.164914.

7. Sahu SK, Motwani BK, Dani A. Prosthetic rehabilitation of edentulous hemimandibulectomy patient: a clinical report. Clin Case Rep 2017;5(11):1739-1742. DOI: 10.1002/ccr3.1125.

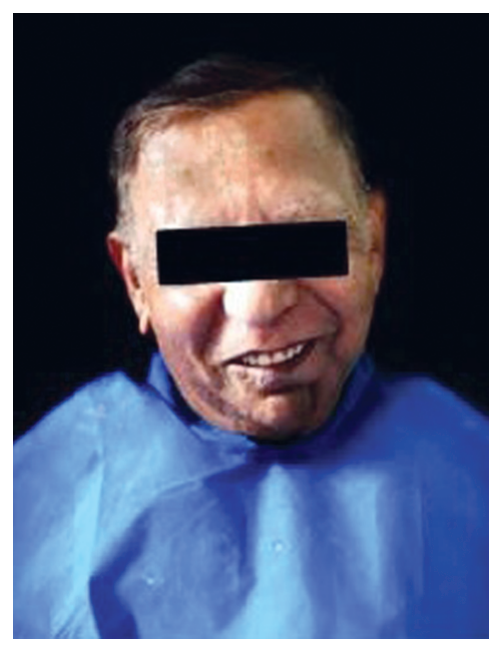

Fig. 9: Posttreatment

8. Mathew A, Thomas S. Management of a hemimandibulectomy defect with a definitive guiding flange prothesis. Pushpagiri Med J 2012;3:132-134.

9. Sharma R, Sharma A, Verma BP, et al. Twin-occlusion prosthesis: A glimmer of hope for hemimandibulectomy patient. Indian J Dent Sci 2019;11:61-64. DOI: 10.4103/IJDS.IJDS_89_18.

10. Ruby KM, Choudhary H. Prosthetic management of hemimandibulectomy patient - a case report. JMSCR 2018;06(07): 158-162. DOI: 10.18535/jmscr/v6i7.26.

11. Beumer 3rd J, Curtis TA, Marunick MT. Maxillofacial Rehabilitation: Prosthodontic and Surgical Consideration. St. Louis: IshiyakuEuroAmerica; 1996. pp. 184-188.

12. Taylor TD. Diagnostic considerations for prosthodontic rehabilitation of the mandibulectomy patient. In: Taylor TD. Clinical Maxillofacial Prosthetics. Chicago: Quintessence Publishing; 2000. pp. 155-170.

13. Beumer 3rd J, Marunick MT, Esposito SJ. Maxillofacial Rehabilitation. 3rd ed., Chicago: Quintessence; 2011. pp. 87-89. (118-20).

14. Goyal P, Manvi S, Arya S. Prosthodontic management of hemimandibulectomy patient: implants, a better solution. J Dent Implant 2016;6:37-40. DOI: 10.4103/0974-6781.190385. 